\title{
Novas Considerações sobre ENSINO E PESQUiSA de História ANTIGA No BRASIL
}

Dominique Santos ${ }^{1}$

Reunir, sistematizar e analisar diversos aspectos e atividades relacionados com a área de História Antiga no Brasil é um desafio muito complexo, que seria possível de ser realizado apenas a partir de uma força tarefa empreendida por vários especialistas deste campo específico do saber ao longo de algumas gerações. Ciente disto, o objetivo do primeiro artigo foi apenas apresentar uma análise a partir de alguns dados fornecidos pela Plataforma Lattes, o que tornou possível algumas reflexões sobre a área, certamente bastante específicas e delimitadas.

A partir da leitura dos comentários a este texto inicial foi possível perceber que os colegas compreenderam a provocação e, a partir do diálogo com esta primeira reflexão, produziram novas indagações, abordaram pontos distintos e apontaram outros problemas, mostrando, assim, a diversidade de perspectivas e leituras que podem ser sistematizadas sobre a área de História Antiga no Brasil.

Alex Degan, por exemplo, apresentou alguns números interessantes sobre o crescimento geral e mundial das matrículas, que saltaram de 13 para 133 milhões de alunos, bem como de Instituições de Ensino Superior, que aumentaram de cerca de 160 para mais de 7.500 entre 1960 e o começo do século XXI. Neste contexto, os Cursos de História também aumentaram de 117 para 346 entre 1973 e 2005. A partir destes dados foi possível interpretar que a área de História Antiga teria, então, acompanhado este crescimento panorâmico, sendo este um dos responsáveis por seu crescimento.

Seria interessante, no entanto, possivelmente em pesquisas futuras, aprofundar a análise destes dados para saber onde estão estas instituições, matrículas e cursos novos. É possível que estejam, em sua maioria, no contexto brasileiro, na Região Sul e Sudeste? Em qual proporção? Como estes dados se configuram na Região Norte e Nordeste do País? Este crescimento de

\footnotetext{
${ }^{1}$ Dominique Santos é Professor de História Antiga na Universidade Regional de Blumenau, onde também coordena o LABEAM - Laboratório Blumenauense de Estudos Antigos e Medievais.
} 
matrículas, que possivelmente também ocorreu nestas regiões, tornou possível a abertura de "vagas novas" para História Antiga? Por que a Região Norte ainda mantém o maior número de Estados sem um único docente especializado nesta área, apesar do crescimento de instituições, matrículas e cursos novos?

Não existe um único Estado sequer nas Regiões Sul, Sudeste e CentroOeste sem docentes de História Antiga, o que não é o caso para o Norte e o Nordeste, uma preocupação também apontada por Katia Pozzer, que sugere o levantamento de dados ao longo do tempo, permitindo uma visualização diacrônica, algo que certamente auxiliaria em um diagnóstico mais preciso da área, mas que, neste momento, não foi possível elaborar.

A História Antiga se constituiu em um dos principais eixos da discussão sobre o currículo de História no Brasil relacionada com a BNCC - Base Nacional Comum Curricular. Entre a primeira e a terceira versão do texto, para mencionar mais uma vez as palavras de Alex Degan, a História Antiga passou de uma "diminuição excludente" para uma "presença imposta". Um dos temas mais frequentes nos discursos que avaliaram a questão foi uma suposta relação entre História Antiga e o assim chamado "Eurocentrismo". Trata-se, sem dúvida, de um debate que existe há muito tempo no interior da área e que precisa ser aprofundado, principalmente ampliando o diálogo com colegas de outras áreas. Todavia, será mesmo que estamos diante de um potencial de contribuições da área de História Antiga ignorado por outros campos ou de um projeto político conscientemente Presentista e "Brasilcêntrico"? É algo que precisa ser perguntado, afinal de contas, a primeira versão da BNCC não causou estranhamento apenas aos historiadores que trabalham com História Antiga. Muito pelo contrário, grupos de trabalho, docentes e pesquisadores das mais diversas áreas, tais como: Medieval, África, América, Contemporânea, Teoria da História, Brasil e até mesmo a própria ANPUH, também se posicionaram de forma crítica àquela versão, que parece ter sido apreciada apenas por quem a elaborou. Uma BNCC que se pretende nacional e diga como a Ciência da História será ensinada na Educação Básica brasileira não pode ser construída sem o diálogo e a presença da ANPUH e dos Grupos de Trabalho de várias áreas.

Nas últimas décadas temos visto a ampliação do envolvimento dos profissionais da área de História Antiga com temáticas mais diretamente 
relacionadas com o Ensino de História, um dos campos da Didática da História, compreendida nos termos delimitados no primeiro artigo e no comentário de Guilherme Moerbeck. Antes estes esforços concentravam-se mais em torno da avaliação de Livros Didáticos e outras atividades diretamente relacionadas ao MEC, mais recentemente, todavia, além deste importante trabalho feito por alguns docentes, temos visto uma maior participação de docentes de Antiga nestas temáticas, seja por meio do PIBID, coordenação de Cursos de Graduação, de Pós-Graduação, que contemplam Ensino de História, participando de NDEs, coordenando estágios, possibilitando uma maior produção de documentários, material para o trabalho com Patrimônio Cultural, atividades educativas em museus, oficinas de realidade virtual e tecnologias 3D, o Ensino nos IFs e assim por diante.

Porém, qual a proporção deste envolvimento? Em que medida os profissionais da área de História Antiga tem integrado os debates relacionados com a Educação Básica de uma forma mais ampla? Como têm se posicionado com relação ao ENEM, ENADE, PNE, PCN/História, Livro Didático, reforma curricular? Tem tido a História Antiga uma participação efetiva no PROFHISTÓRIA? Como? O mestrando profissional em Ensino de História não precisará produzir conhecimentos também nesta área do conhecimento histórico? Por que não há nos encontros da ANPUH Nacional GT para discutir o Ensino de História Antiga?

Certamente, são temas que devem interessar à área como um todo, e não ficarem restritos aos Cursos de Licenciatura. Não pode haver hierarquização entre Ensino e Pesquisa. Comentando a atuação dos classicistas estadunidenses no debate sobre História Global, Elizabeth Ann Pollard (2008) nos adverte que, por não participarem e não se engajarem profundamente neste tipo de discussão, historiadores de Grécia e de Roma acabaram por deixar outros ocuparem seus lugares e construírem as agendas mais importantes, ignorando questões fundamentais e gerando resultados catastróficos. É este o caso no Brasil? Isto está ocorrendo? Foi preciso a BNCC para chamar atenção dos docentes de História Antiga para tais aspectos? Ou os debates sobre Ensino de História Antiga ocorrem, porém no interior do campo? Trata-se de uma discussão pedagógica, metodológica e teórica? Ou, de fato, muito mais política? 
Acompanhando reflexões recentes sobre a área de História Antiga no Brasil propostas por Norberto Luiz Guarinello, Luís Ernesto Barnabé aponta um importante questionamento sobre as formas utilizadas pelos pesquisadores da área para se referir as suas próprias pesquisas. É possível que estejam delimitando suas temáticas às formas consagradas (Grécia, Roma...), por conta de um relacionamento com o mercado editorial, com a História Pública, o senso comum e outras instâncias, como a própria exigência da Plataforma Lattes de solicitar por meio de palavras-chave que os docentes delimitem uma grande área de atuação, acompanhada de uma subárea de especialização. Assim, se, por um lado, é possível utilizar este sistema de classificação para fazer o mapeamento proposto, também é preciso lembrar que os pesquisadores da área estão cientes de temas mais amplos, como os apontados por ele. É uma questão também lembrada por Gilberto Francisco, quando afirma em seu comentário que "Grécia" e "Roma" são "áreas de interesse", e que elas provavelmente escondem um repertório variado, além do próprio Alex Degan, que mencionou também as discussões relacionadas com o Mediterrâneo Antigo, dentre outras.

Há um outro aspecto do trabalho que Barnabé vem desenvolvendo que é muito importante para a área de História Antiga, e que seu comentário nos faz lembrar: sua investigação sobre a vida e a obra de Justiniano José da Rocha. Apesar de recente, quando em comparação com outros países, a História Antiga já tem uma trajetória enquanto área no Brasil que pode, deve e precisa ser historicizada. Alguns esforços têm sido feitos neste sentido, boa parte deles já mencionado no primeiro texto e nos comentários a este relacionados. No entanto, o trabalho de Barnabé sobre a obra de Justiniano da Rocha tem mostrado que é preciso ainda muito esforço para que consigamos compreender com maior profundidade a História da História Antiga no Brasil.

O Arquivo Eurípedes Simões de Paula (AESP), por exemplo, contém uma grande quantidade de documentos: 3.428 textuais; 4.575 audiovisuais; 182 tridimensionais (Theodoro, 2009). Este material abrange vários aspectos das atividades de Simões de Paula: discente, docente, administrativa etc., além de documentos reunidos por sua esposa depois do falecimento deste. Este material está arquivado a partir de uma divisão em série. A segunda delas, denominada de "Série II", possui, dentre outras coisas, por exemplo, "material didático constituído de fichas de aulas, fichamento de livros, apontamentos, traduções, 
textos de cursos da então cadeira de História da Civilização Antiga e Medieval” (Theodoro, 2009, p. 62). A assim denominada "Série III", por sua vez, cataloga as correspondências de Simões de Paula, muitas delas com universidades e colegas do Brasil e internacionais, dentre eles Fernand Braudel e os professores franceses que auxiliaram na organização do Curso de História da FFCL-USP (Theodoro, 2009, p. 62). Ou seja, trata-se de material riquíssimo e de profundo interesse para a área, precisa ser explorado por vários pesquisadores, recebendo tratamento semelhante ao que Barnabé está tentando conferir à obra de Justiniano da Rocha. A vasta produção, documentação e correspondências de Emanuel Bouzon e Ciro Flamarion Cardoso também renderiam importantes e necessárias pesquisas para a área de História Antiga no Brasil.

Acertadamente, Gilberto Francisco chama atenção para o fato de que a temática do Ensino poderia ser mais explorada no primeiro texto. Considerando este aspecto e respondendo à necessidades desta natureza, novas reflexões foram elaboradas tendo por base a análise dos planos de ensino dos docentes de História Antiga, contendo algumas comparações com os dados da Plataforma Lattes. Em breve, elas estarão disponíveis em forma de capítulo integrando o livro organizado por José Maria Gomes de Souza, da Universidade Estadual de Pernambuco, Renan Birro, da Universidade Federal do Amapá, e Guilherme Moerbeck, da Universidade Estadual do Rio de Janeiro, já mencionado no comentário deste último.

É preciso considerar ainda que o Currículo Lattes de fato tem por objetivo registrar atividades acadêmicas, sobretudo de pesquisa, conforme o autor lembra em seu comentário. Porém, nele também são registrados: a participação em eventos relacionados com a docência; cursos de formação voltados às atividades pedagógicas; atividades e publicações relacionadas com o PIBID; publicações relacionadas com o PIBIC Ensino Médio etc. Isto significa que vários artigos registrados como parte da produção acadêmica da área podem ser compreendidos como pesquisa, mas eles são, ao mesmo tempo, reflexões diretas sobre resultados obtidos na docência ou pesquisas cuja docência em História Antiga foi o foco principal. Além disso, todas as 116 pessoas, talvez com uma ou outra exceção, são contratadas ou concursadas para exercer a função pública de professor/a de História Antiga em um Curso ou Departamento de História. Isto significa que estas são as pessoas responsáveis 
por ensinar História Antiga no País. O que temos nos currículos registrados na Plataforma Lattes são os resultados do que os docentes brasileiros de História Antiga produziram nas categorias Ensino, Pesquisa e Extensão. O artigo inicial se preocupou em discutir algumas destas questões, como, por exemplo, onde estes docentes estudaram, que idiomas antigos e modernos conhecem, em que área atuam, para onde viajam para participar de eventos acadêmicos etc. Talvez pesquisas futuras possam aprofundar a análise, problematizando, por exemplo, temáticas específicas relacionadas com a docência.

Outra sugestão interessante apresentada no comentário de Gilberto Francisco é a realização de tabelas e gráficos que abordassem outros aspectos capazes de serem percebidos pela análise dos dados disponíveis. Poderia ser abordado o gênero, a formação, o ano desta formação, quantos pesquisadores formaram-se em uma Licenciatura, quantos optaram pelo Bacharelado, ou ainda a dupla formação, e um último fator muito interessante para os dias atuais: quanto tempo foi necessário investir na formação da Graduação até o Doutorado e, depois deste investimento, quanto tempo foi necessário para que determinado docente conseguisse emprego na área.

Muitos pesquisadores não informam em seus currículos se possuem Licenciatura, Bacharelado ou as duas modalidades, apenas: "Graduação" + a área de atuação, geralmente História. Além disso, algumas decisões precisariam ser tomadas. Por exemplo, o que consideraremos emprego? Pleno emprego? Concurso Público? Vaga efetiva? Todas estas questões precisariam ser decididas. No que diz respeito ao primeiro item, o que compreenderemos por "gênero"? Trata-se da simples identificação biológica? De sentimento de pertencimento identitário a determinado gênero? Como identificaremos isto? Trata-se também de uma questão que precisa ser discutida. É possível dizer, no entanto, que dos 116 docentes de História Antiga, 67 estão registrados como sendo do sexo masculino (57.75\%) e 49 como sendo do feminino (42.25\%).

Quando o GTHA foi fundado, Fábio Faversani estava preocupado com a necessidade de levantamento de dados acerca do Ensino e da Pesquisa sobre História Antiga no Brasil, pois acreditava que a partir deles a área poderia ser mais bem conhecida por seus próprios pesquisadores e pelos nela interessados. O breve histórico do GTHA, e de seu Banco de Dados, sistematizado por Juliana Bastos Marques e Anderson Vargas, e continuado por outras pessoas, bem como 
as reflexões produzidas ao longo deste debate, mostrou que Faversani estava correto quando percebeu a importância de pesquisas desta natureza. As demandas institucionais e pressões do universo acadêmico, como, por exemplo, a necessidade de uma especialização bastante delimitada e de um produtivismo cada vez maior, fatores apontados por Rafael da Costa Campos como problemas a serem enfrentados, não devem impedir, assim, este tipo de investigação, pois, apesar de ser uma tarefa exaustiva e de difícil execução, pesquisas como esta sistematizam informações interessantes, que podem ser utilizadas de várias maneiras, inclusive para o mapeamento de novos caminhos, direcionamentos, estratégias e perspectivas para a área de História Antiga no Brasil. 


\section{Referências Bibliográficas}

Pollard, Elizabeth Ann. Placing Grego-Roman History in World Historical Context. Classical World, Volume 102, Number 1, Fall 2008. Pp. 53-68.

Theodoro, Janice. Eurípedes Simões de Paula. Revista de História, $\mathrm{n}^{0} 160$. Dossiê Eurípedes Simões de Paula ( $1^{\circ}$ semestre de 2009), p. 17-50. 